Cardiac response to shock in curarized dogs: 1.fiects of shock intensity and duration. warnine vinal. and prior experience with shock. Journal of Comparative \& Phy siological Pyithology. 1966,62,1-7.

IITZ(;FRALI), R, D.. \& VARDARIS, R. M. Classical conditioning of heart rate deceleration in the rat with continuous and partial reinforcement. Pyychonomic Science. $1966,6,437-438$

HOLDSTOCK. T. L.. \& SCHWARTZBALM, J. S. Classical conditioning of heart rate and salvanic skin response in the rat. Psychophysiology. 1965, 2, 25-38.

JACOBSON. A. L. HOROWTTZ, S. D., \& I RIFD. C. Classical conditioning, pseudoconditioning. or sensitization in the planarian. Journal of Comparative \& Physiological Psychology, 1967, 64, 73-79.

KIMBLI: $\mathrm{G}_{\text {. A. Hilgard and Marquis }}$
Conditioning and learning. New York Appleton-Century-Crofts. 1961. Pp. 59-65.

WILLER, R. I... BANKS. J. H.. JP.. \& CACL. IV. 1. Cardiac conditioned responses in avoidance and yoked-control rats. Psychonomic Science. 1967.9.581-582.

OVERMIER, 3. B. Instrumental and cardiac indices of Pavlovian fear conditioning as a function of US duration. Joumal of Comparative \& Physiological Psychology. $1966,62,15-20$.

\section{NOTES}

1. This investigation was supported in part by a research grant (IM-487 C-15) from the National Institute of Mental Health of the National Institutes of Health, United States Public Health Service, and in part by the Commonwealth of Pennsylvania.

2. Now at U.S. Army Behaviorał Science Research Laboratory, Washington. D.C.

\title{
Further study of "learned" activity in food-deprived rats
}

\author{
TOMI S. ALLISON, ${ }^{2.3}$ Washington State \\ University, Pullman, Wash. 99163
}

Twenty rats were maintained on a 21-h food-deprivation schedule in activity wheels for 35 days. Ten Ss had freedom to run right up to feeding time daily and 10 were blocked out of the wheels during the last hour before feeding to reduce any reinforcing effect of feeding on running. Wheel running increased significantly from the third to second hours before feeding in both groups, but there was no significant difference between groups. Food presentation was observed to be contingent upon being in side cages rather than upon running in $S s$ fed immediately after opportunity to run. The findings did not support the hypothesis of Reid \& Finger (19.55) that increased wheel running prior to feeding is a function of reinforcement of running by subsequent feeding.

Activity-wheel running in food-deprived rats increases markedly as feeding time approaches (Reid \& Finger, 1955). The hypothesis that this phenomenon results from reinforcement of running due to temporal proximity to feeding (Reid \& Finger, 1955) has been strengthened by reports that rats that are fed immediately after their last opportunity for running run more than rats that are blocked out of the wheel for $1 \mathrm{~h}$ before feeding (Finger, Reid. \& Weasner, 1957; Hall, 1958). The present experiment was undertaken to test this hypothesis further.

One problem with the experiments by Finger et al (1957) and Hall (1958) is that the investigators compared wheel running for different hours in their groups. Running during the last hour before feeding in immediately fed $S s$ was compared with running during the hour beginning $2 \mathrm{~h}$ before feeding in Ss that were blocked from the wheels during the last hour before feeding. Therefore, it is not clear if the differences between groups were a function of differences in temporal proximity of running to feeding or the difference in temporal proximity of the comparison hours to feeding.

In the present experiment, wheel running during the second and third hours before feeding was compared between Ss fed immediately after opportunity for running and Ss blocked from the wheels for $1 \mathrm{~h}$ before feeding. Thus, the two comparison hours (second and third before feeding) were the same for both groups, but one group could run during the last hour before feeding and one group could not run. In addition, the relationship between running and events at feeding time was analyzed for possible reinforcing contingencies.

\section{SUBJECTS AND APPARATUS}

Twenty male hooded rats, 110 days old at the start of habituation, from the colony at Washington State University, were housed throughout the experiment in standard Wahmann activity wheels equated for sliding torque by the method of Lacey (1944) and equipped with cardboard side panels to reduce interaction among Ss. Wheel revolutions were recorded from outside the experimental room by magnetic counters and a 20-pen event recorder. A 12-h light cycle was maintained by an automatic timer. Room temperature was maintained at $72^{\circ} \mathrm{F}$.

\section{PROCEDURE}

The Ss were first given a 7-day habituation period in the wheels under ad lib food and water conditions. A 21-h food-deprivation schedule, with water continuously available, was begun after the 7 th day of habitaution and continued for 35 days. The $E$ entered the experimental room daily at the start of the last hour before feeding to block the delayed-feeding (DF) Ss out of the wheels and to check the immediate-feeding (IF) Ss. A second entry occurred at the end of the hour to feed Ss in both groups. Group DF Ss were again given access to the wheels after food was placed in the side cages. Remaining food was removed from the side cages after $3 \mathrm{~h}$ of feeding, and water supplies were replenished. The two groups of $10 \mathrm{Ss}$ each were run in succession due to equipment and facility limitations, but care was taken to equate extraneous conditions as closely as possible between groups.

Data were collected daily throughout the deprivation period. Magnetic counter readings were recorded for the $3 \mathrm{rd}$ and $2 \mathrm{nd}$ hours before feeding. Event recordings were obtained daily for the 2 nd hour before feeding in both groups and for the last hour before feeding in Group IF.

RESULTS AND DISCUSSION

The mean number of wheel revolutions, for blocks of 5 days, from the second (Hour 2) and third (Hour 3) hours before feeding are shown in Fig. 1. Only the data from the last block of 5 days were analyzed since concern was with the final level of activity produced by deprivation training. Groups by Hours interaction was not significant $(F<1)$. The difference in amount of running between the second and third hours before feeding was significant $(F=17.63, \mathrm{df}=1 / 18, \mathrm{p}<.01)$, indicating that deprivation training did produce a significant increase in running during Hour 2. However, the difference between groups was not significant $(F<1)$ and, in fact, was opposite to the prediction that would be made by the reinforcement hypothesis.

The relationship between running and events at feeding time was analyzed by timing E's entries at feeding time against event records of running in Group IF and by direct observation at feeding time. Any 


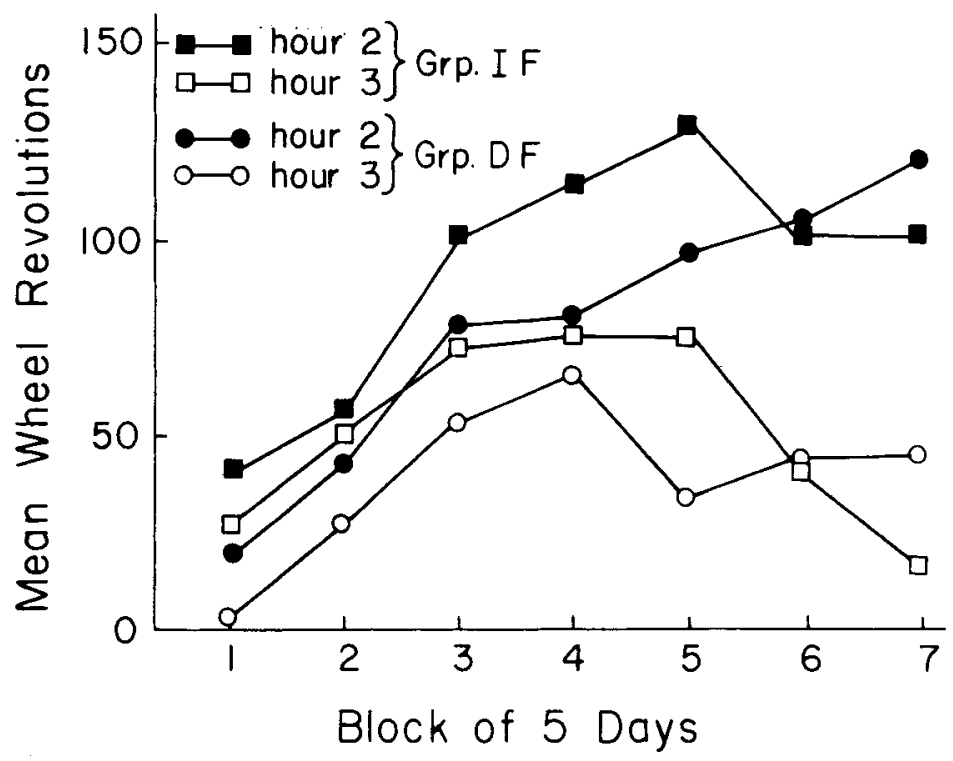

instance of running within $1 \mathrm{~min}$ prior to E's entry was counted as a contingency. The median number of such contingencies over the first 15 days of deprivation, during which the greatest increase in running occurred, was zero for all Ss in the IF group. Thus, it is unlikely that this potential source of conditioned reinforcement of running could account for the increased running that occurred. Bursts of running frequently followed E's entries, but after the first 5 days of deprivation the $S s$ were almost invariably in the side cages when food was presented. Thus, food was contingent upon being in the side cage rather than running in the wheel.
Fig. 1. Mean wheel revolutions for the second and third hours before feeding in Groups IF and DF

implied, the 1-h delay between running and feeding in the present study should have reduced the amount of running in the DF group relative to the IF group. Therefore, it is concluded that increased wheel running before feeding in food-deprived rats does not result from reinforcement of running by feeding or by temporal proximity to feeding.

\section{REFERENCES}

HALL, J. F. The influence of learning in activity wheel behavior. Journal of Genetic Psychology, 1958, 92, 121-125.

FINGER, F. W., REID, L. S.. \& WEASNER, M. $H$. The effect of reinforcement upon activity during cyclic food deprivation. Journal of Comparative \& Physiological Psychology, $1957,50,495-498$.

The Reid \& Finger (1955) reinforcement hypothesis suggests only that temporal proximity of running to feeding is necessary to produce increased running before feeding; exact contingencies between running and feeding are not suggested. Thus, failure to find contingencies between running and potentially reinforcing events at feeding time in the present study would not constitute direct evidence against the Reid $\&$ Finger (1955) hypothesis. However, it is difficult to see how feeding could reinforce running when food presentation is contingent upon not running. Furthermore, even if exact contingencies are not necessary, as Reid \& Finger (1955)
LACEY, O. L. A revised procedure for the calibration of the activity wheel. American Journal of Psychology, 1944, 57, 412-420.

REID, L. S., \& FINGER, F. W. The rat's adjustment fo 23-hour food-deprivation cycles. Journal of Comparative \& Physiological Psychology, 1955, 48, 110-113. NOTES

1. Portions of this paper were submitted at Washington State University in partial fulfillment of requirements for the MS degree in psychology and also were read at the joint Washington-Oregon Psychological Association

2 . The author expresses his appreciation to his advisor, K. E. Lloyd, for his encouragement and suggestions regarding the present study.

3. During the present research the author was supported by a research traineeship from the National Aeronautics and Space Administration. Convention at Gearhart, Oregon, May 1-3, 1969. 